Lechin, F., Gomez, F., Van Der Diss, B. \& Lechin, E. (1986a) Distal colon motility in schizophrenic patients. Journal of Clinical Pharmacology, 20, 459-64.

- Van Der Diss, B., Gomez, F., Valls, J. M., Acosta, E. \& AROCHA, L. (1980b) Pharmacomanometric studies of colonic motility as a guide to the chemotherapy of schizophrenia. The Journal of Clinical Pharmacology, 20, 664-71.

- (1979a) Effects of dopaminergic blocking agents on distal colon motility. Journal of Clinical Pharmacology, 19, 617-25.

Digestive Diseases and Sciences, 24, 86-7.

(1981a) Colon motility and psychological traits in irritable bowel syndrome. Digestive Diseases and Sciences, 26, 474-5.

(1981b) Clonidine therapy for psychosis and tardive dyskinesia. American Journal of Psychiatry, 138, 390.

- (in press) Intestinal pharmacomanometry and glucose tolerance: evidences of two antagonistic dopaminergic mechanisms in the human. Biological Psychiatry.

\section{DRUG SIDE-EFFECTS AND BRAIN DAMAGE}

DeAr Sir,

Neuroleptic drugs induce extrapyramidal disturbances which mimic Parkinson's disease, but this is not taken to mean that they can cause Parkinson's disease: a patient whose Parkinsonism continues long after neuroleptic withdrawal is assumed to have been suffering from incipient Parkinson's disease. Involuntary movement disorders are another group of extrapyramidal disturbances and, a priori, it would hardly be surprising if neuroleptics induced conditions mimicking these. Such extrapyramidal disturbances would likewise be expected to be reversible on drug withdrawal; if the disorder persisted, the directly analogous inference to be drawn is that an underlying disease process was responsible.

For several years psychological (Johnstone et al, 1981 ; Owens and Johnstone, 1980) and radiological (Weinberger et al, 1979) evidence has been accumulating of organic brain damage in chronic schizophrenics unrelated to drug treatment, and further studies (Kleinman, 1981 ; Andreasen, 1981; Owens, 1981), described at the recent Annual Meeting of the Royal College of Psychiatrists, indicate an association between brain damage, irreversible movement disorder, and negative symptoms in chronic schizophrenic patients. It is thus becoming increasingly apparent that the involuntary movement disorders seen in neuroleptic-treated schizophrenic patients may be categorized as either drug-induced, if drug withdrawal is followed by their disappearance, or as the result of structural brain disease with or without superimposed drug-induced effects, if the movements persist following drug withdrawal.

The term 'tardive dyskinesia' should be reserved for those cases in whom irreversible movement disorders occur late in the course of the schizophrenic or other brain disease processes.

\section{E. R. Squibb \& Sons Ltd,}

A. A. Schiff

147-49 Staines Road,

Hounslow TW3 3JA

\section{References}

ANDREASEN, N. (1981) Positive and Negative Symptoms in Relation to CT Scan Findings. Paper given at Annual Meeting of The Royal College of Psychiatrists.

Johnstone, E. C., Crow, T. J., Frith, C. D., Stevens, M., KreEL, L. \& Husband, J. (1978) The dementia of dementia praecox. Acta Psychiatrica Scandinavica, 57, 305-24.

Kleinman, J. (1981) CT Scan Studies at N.I.M.H. Paper given at Annual Meeting of The Royal College of Psychiatrists.

OwENs, D. G. C. (1981) Do Neuroleptic Drugs Cause Tardive Dyskinesia? Paper given at Annual Meeting of The Royal College of Psychiatrists.

_ \& Johnstone, E. C. (1980) The disabilities of chronic schizophrenia-their nature and the factors contributing to their development. British Journal of Psychiatry, 136, 384-95.

Weingerger, D. R., TORReY, E. F., Neophytides, A. N. \& WYATr, R. J. (1979) Lateral cerebral ventricular enlargement in chronic schizophrenia. Archives of General Psychiatry, 36, 735-9.

DeAR SIR,

\section{SUICIDE IN FAMILIES: DRAW A LIFE-CHART}

The suicidal family described by Dr Khin-MaungZaw (Journal, July 1981, 139, 68-69) is of considerable interest as an example of violent suicide and non-fatal deliberate self harm in several members of a family extending over more than one generation and including suicide in identical twins. Whether it is at least likely that there was a genetic predisposition to violent suicide in the family' does however still seem to be a matter for conjecture on the basis of the evidence presented in the paper, and the interactional effects of illness events may well have been more important than the author suggests.

To illustrate this, I have tabulated the data along the lines of a Meyer life chart which demonstrates how the suicides seem to have triggered the onset of 
depression (single episode or recurrent) in other family members.

It is again a matter of conjecture whether these temporal links signify causal relationships, but the table does illustrate how useful it can be to set out complex clinical data in a way that does full justice to temporal relationships between events. Time spent in completing a Meyerian life chart is so often amply rewarded that such a technique ought to be an integral part of any psychiatric case history.

H. G. Morgan

University of Bristol,

Department of Mental Health,

39-4I St Michael's Hill,

Bristol BS2 8DZ

TABLE

Preceding suicides in paternal greatgrandfather (cut throat) and maternal grandmother (cut throat)

\begin{tabular}{|c|c|c|c|c|c|}
\hline & Twin 1 & Twin 2 & Father & Mother & Maternal grandmother \\
\hline 1970 & $\begin{array}{l}\text { Suicide (shot self) } \\
\text { age } 21\end{array}$ & $\begin{array}{c}\text { Depression } \\
\text { (In-patient: } E C T)\end{array}$ & & $\begin{array}{c}\text { Grief } \\
\text { Depression } \\
\text { (out-patient: ECT) }\end{array}$ & \\
\hline 1971 & & & & $\begin{array}{c}\text { Depression } \\
\text { (Out-patient: ECT) }\end{array}$ & \\
\hline 1972 & & & & $\begin{array}{c}\text { Depression } \\
\text { (Out-patient: ECT) }\end{array}$ & \\
\hline
\end{tabular}

1973

1974

Depression (In-patient) age 74

1975

1976

1977

1978

Depression

(Out-patient: ECT)

1979

July: Depression

(In-patient: ECT)

Recovered

Sept: Married

Dec: Depression

Suicide (shot self)

Depression (preceded son's suicide)

1980

Depression:

cut wrists

and throat

(In-patient: ECT)

1981

Continuing

In-patient

Treatment

Depression

(Out-patient:

antidepressants)

Continuing

depression 